\title{
Antibody to synthetic poly dAT: correlation with antibody to native DNA and specificity for SLE
}

\author{
PAUL DAVIS AND DREW MAKINEN \\ From the Rheumatic Disease Unit, Department of Medicine, University of Alberta, Edmonton, Alberta, \\ Canada T6G 263
}

SUMmARY Antibodies to synthetic ${ }^{3} \mathrm{H}$-poly dAT have the advantage over antibody to native DNA in that they have a higher degree of specificity for systemic lupus erythematosus (SLE). This is because poly dAT eliminates the problem of measurement of single stranded antibodies that are not specific for any one condition but which may be detected by native DNA preparations which usually contain single stranded regions. The overall degree of correlation between the two antibodies is good in SLE. Antibodies to poly dAT correlate well with clinical evidence of disease activity but in this study were not particularly associated with the presence of renal disease.

It has been reported that antibodies to double stranded DNA occur exclusively in the sera of patients with systemic lupus erythematosus (SLE) ${ }^{1}$ and that the amount of antibody present correlates with disease activity and is therefore useful in both the diagnosis and therapeutic monitoring of the disease. $^{2} 3$ In subsequent reports, there has been some discrepancy in the specificity of these antibodies which has probably been due to the contamination of the native DNA used in the assay systems with either single stranded DNA or duplex DNA with single stranded regions. ${ }^{4-6}$ This inevitably results in the detection of antibodies to both double stranded and single stranded DNA as well as antibodies to other non-nucleic acid antigenic contaminants. ${ }^{7}$ The overall result has been the reports of antibodies to DNA occurring in a wide number of connective and chronic inflammatory diseases.

One attempt at solving this problem was to filter native DNA using a nitrocellulose filter, since these filters of $0.45 \mu \mathrm{m}$ pore size retain both single stranded DNA and protein- $n$-DNA complexes but allow $n$-DNA to pass through. ${ }^{8}{ }^{9} \mathrm{This}$, however, does not exclude DNA with single stranded regions. Alternative techniques such as MAK column chromatography ${ }^{10}$ and benzoylated naphthoylated DEAE cellulose columns ${ }^{11}$ are more efficient but do not solve the problem entirely.

The use of synthetic polynucleotides will potentially eliminate some of these problems. ${ }^{7}$ Synthetic poly dAT does not contain single stranded regions under the conditions of the assay and is considered

Received for publication 31 August 1979 to possess all, or most of, the binding sites intrinsic to naturally occurring DNA, because the antigenic sites responsible for binding anti- $n$-DNA are located on the exposed deoxyribose-phosphate backbone and are independent of the individual bases..$^{12}$

Poly dAT, therefore, provides a uniform and completely double stranded antigen that could be used in the detection of antibodies which react specifically with duplex DNA. This study reports results using this antigen with a standard radioimmunoassay in 923 serum samples from patients with a variety of connective tissue diseases. In addition, the correlation between antibodies to poly dAT was compared to antibodies to a well characterised native DNA preparation in 398 serum samples from patients with SLE.

The results of poly dAT binding were also correlated with disease activity in 37 patients from whom multiple samples had been obtained over a variable time course.

\section{Material and methods}

Sera from a total of 195 non-laboratory controls, 65 patients with Crohn's disease, 20 patients receiving haemodialysis, 398 samples from 107 patients with SLE, and 245 samples from patients with other connective tissue diseases were tested for antibodies to native DNA and poly dAT using the Millipore Filter Assay.

In the case of the sera from patients with SLE, a comparative study of binding to both poly dAT and a well characterised native DNA preparation was performed. In 37 cases of SLE, all of whom ful- 
filled the Arthritis and Rheumatism Association preliminary criteria for the classification of the disease, serial levels of poly dAT binding were correlated with clinical evidence of disease activity.

\section{DISEASE ACTIVITY}

Clinical evidence of disease activity was assessed by the presence of currently active clinical signs or symptoms and independently of knowledge of levels of DNA and poly dAT antibodies and complement levels. Emphasis was placed on the presence of an actively changing clinical picture rather than evidence of previous but currently quiescent disease. The following variables were assessed: skin rash, mouth ulcers, increased hair loss, synovitis, pleurisy, pericarditis, serositis, myositis, deteriorating CNS involvement, deteriorating renal function. In addition, patients were divided into renal and non-renal groups. Twenty-two patients were included in the renal group and had either biopsy evidence of active renal disease (11 patients) or an active urinary sediment (cellular casts and proteinuria $>500 \mathrm{mg} / 24 \mathrm{~h}$ ). The remaining 15 patients had no clinical evidence of renal disease.

MILLIPORE FILTER ASSAY 13

In the binding assay procedure, $100 \mu{ }^{3} \mathrm{H}$-poly dAT, $0.532 \mu \mathrm{g} / \mathrm{ml}$, in citrate buffer, $\mathrm{pH} 7.0$, were added to $25 \mu$ l heat inactivated serum in $12 \times 75 \mathrm{~mm}$ glass tubes. Blanks, consisting of $100 \mu \mathrm{l}^{3} \mathrm{H}$-poly dAT and $25 \mu \mathrm{l}$ citrate buffer were included with each individual run. The mixture was incubated at $37^{\circ} \mathrm{C}$ for 15 minutes, and the reaction was then stopped by adding $4 \mathrm{ml}$ cold citrate buffer, $\mathrm{pH} \mathrm{8.0.} \mathrm{The} \mathrm{diluted}$ mixture was passed through pre-wet HAWP Millipore filters (pore size $0.45 \mu \mathrm{m}$ ) using gentle vacuum. Both the reaction tubes and the filter were washed twice with $4 \mathrm{ml}$ citrate buffer and once with $4 \mathrm{ml}$ distilled water. The filters were then placed in glass scintillation vials and dried. Upon drying, $10 \mathrm{ml}$ DPO toluene scintillation fluid was added. The samples were counted in a liquid scintillation counter. The binding serum was determined by taking the number of counts in the sample, subtracting the number of counts in the blank, and dividing by the total number of counts in $100 \mu \mathrm{l}$ ${ }^{3} \mathrm{H}$-poly dAT. Results were expressed as a percentage.
${ }^{3}$ H- POLY dAT SYNTHESIS

The ${ }^{3} \mathrm{H}$-poly dAT employed in this study was prepared by combining $1.25 \mathrm{ml}$ of $1.0 \mathrm{M} \mathrm{KPi}$ $\left(1.0 \mathrm{M} \mathrm{KH} \mathrm{KHO}_{2}\right.$ adjusted to $\mathrm{pH} 7.5$ with $10.0 \mathrm{M}$ $\mathrm{KOH}), 0.50 \mathrm{ml} \mathrm{0.1} \mathrm{M} \mathrm{MgCl}_{2}, 50 \mu \mathrm{l} 0.1 \mathrm{M}$ deoxyadenosine $5^{1}$ triphosphate, $2.5 \mathrm{ml} 2 \mathrm{mM}^{3} \mathrm{H}$ thymidine $5^{1}$ triphosphate $(15000 \mathrm{cpm} / \mathrm{nmol}), 150 \mu \mathrm{l}$ DNA polymerase $1,20.3 \mathrm{ml}$ distilled $\mathrm{H}_{2} \mathrm{O}$, and $250 \mu \mathrm{l}$ poly dAT (13.4 $\left.\mathrm{A}_{260}\right)$ together in a glass $13 \times 100$ $\mathrm{mm}$ tube. The mixture was incubated at $37^{\circ} \mathrm{C}$ and checked hourly on a Turner model 430 spectrofluorometer by the ethidium bromide assay. ${ }^{14}$ When the ${ }^{3} \mathrm{H}$-poly dAT fluorescence reached a peak the reaction was stopped by immersing the poly dAT mixture in a $95^{\circ}$ waterbath for 5 minutes.

The poly dAT was then concentrated in a cellodian bag to $1.0 \mathrm{ml}$ and run over a $0.5 \mathrm{~mol} / \mathrm{l}$ agarose column to be purified.

After purification, the ${ }^{3} \mathrm{H}$-poly dAT was diluted to the desired storage concentration with $10 \mathrm{mM}$ Tris $0 \cdot 1 \mathrm{mM}$ EDTA, pH $8 \cdot 0$, and stored at $-20^{\circ} \mathrm{C}$.

The ${ }^{3} \mathrm{H}$-poly dAT used in the study was tested for double stranded purity by the ethidium fluorescence technique which indicated a $100 \%$ duplex structure.

\section{NATIVE DNA}

In this study an Escherichia coli DNA was used (kindly provided by Wampole Labs, Cranbury, New Jersey, USA). This preparation was labelled with ${ }^{125}$ I and found to be $85 \%$ duplex in structure using the ethidium bromide assay.

\section{Results}

The number of sera which bound to the native DNA preparation and the poly dAT are tabulated in Table 1. Upper limits of normal with both antigens were calculated as the mean +2 SD of binding in the normal group. Of the 923 sera tested, elevated levels of binding to poly dAT were seen almost exclusively in patients with SLE. Sera from two controls bound $7 \%$ and $8 \%$, and serum from one patient with Felty's syndrome bound $7 \%$. Levels of poly dAT binding were not elevated in 175 patients with rheumatoid arthritis, 26 with progressive systemic sclerosis, 25 with ankylosing spondylitis, or 65 with Crohn's disease (included as a chronic inflam-

Table 1 Number of sera positive for DNA antibodies: E. coli ${ }^{125}$ I $n$-DNA and synthetic poly dAT

\begin{tabular}{llllllll}
\hline & $\begin{array}{l}\text { Normals } \\
n=195\end{array}$ & $\begin{array}{l}R A \\
n=175\end{array}$ & $\begin{array}{l}\text { Felty's } \\
n=19\end{array}$ & $\begin{array}{l}\text { Crohn's } \\
n=65\end{array}$ & $\begin{array}{l}\text { PSS } \\
n=26\end{array}$ & $\begin{array}{l}\text { AS } \\
n=25\end{array}$ & $\begin{array}{l}\text { SLE } \\
n=398\end{array}$ \\
\hline $\begin{array}{l}\text { E. coli }{ }^{125} \text { I n-DNA } \\
\begin{array}{l}>10 \% \\
\text { poly dAT }>6 \%\end{array}\end{array}$ & 19 & 14 & 9 & 7 & 0 & 4 & 115 \\
\hline
\end{tabular}

PSS = progressive systemic sclerosis; AS = ankylosing spondylitis. 
matory, non-connective tissue disease). In contrast, binding to the native DNA preparation was less specific with a high prevalence of abnormal results in normals and connective tissue diseases. In addition, a greater number of sera from the patients with SLE bound to the native DNA than to the poly dAT.

The degree of correlation between antibodies to native DNA and poly dAT are shown in Table 2 .

Table 2 Results of n-DNA and poly dAT binding in 398 sera from 107 patients with SLE

\begin{tabular}{lll}
\hline & DNA binding & No. of sera \\
\hline n-DNA and & Normal & 270 \\
poly dAT & Elevated & 84 \\
n-DNA & Elevated & 33 \\
poly dAT & Elevated & 11 \\
& Total & 398 \\
\hline
\end{tabular}

Results represent abnormal levels in 398 sera from 107 patients with SLE. The overall degree of correlation between the two tests was good when all sera were included $(r=0.97, \mathrm{P}<0.01)$. The degree of correlation was not so good when only sera with one or both tests were abnormal but was still significant $(r=0.76, P<0.05)$. This difference was due to sera which bound to either one or other of the preparations but not to both. This was particularly prevalent with the native DNA preparation where 33 samples gave abnormal results to this antigen alone (mean level $19 \%$ ). In some cases the degree of elevation was marked with levels greater than $20 \%$ in 10 instances. Binding to poly dAT alone was less common, occurring in only 11 samples (mean level $11 \%$ ). Markedly elevated binding was not seen with poly dAT in the presence of normal binding to native DNA.

The correlation between increased levels of poly dAT binding and clinical disease activity is shown in Table 3. The results represent abnormal poly dAT

Table 3 Results of poly dAT binding in relation to clinical activity

\begin{tabular}{llrr}
\hline & Renal & $29 / 57$ & \\
Active & Non-renal & $15 / 33$ & $44 / 90$ \\
& Renal & $0 / 99$ & \\
Inactive & Non-renal & $9 / 61$ & $9 / 160$ \\
& & \\
\hline
\end{tabular}

levels in 250 sera from 37 patients with SLE followed for a period of not less than six months. These results show a significant correlation between clinical evidence of disease activity and elevated levels of poly dAT binding $\left(\chi^{2}=65.03, \mathrm{P}<0.001\right)$. This degree of significant correlation was true for disease activity in both renal and non-renal groups. There was, however, no correlation between the presence or absence of antibodies to poly dAT and the renal and non-renal groups $\left(\chi^{2}=1 \cdot 62, P=0 \cdot 20\right)$.

\section{Discussion}

Although it is reported that antibodies to native DNA are specifically found in the sera of patients with SLE and that levels correlate with disease activity, this is not universally accepted. Following the original reports of antibodies to native DNA in patients with SLE, there have been subsequent studies reporting the presence of these antibodies in the sera of normal laboratory controls, ${ }^{15}$ patients with connective tissue diseases including progressive systemic sclerosis, ${ }^{16}$ mixed connective tissue disease, ${ }^{17}$ both rheumatoid and juvenile rheumatoid arthritis, ${ }^{18}$ and in other chronic inflammatory diseases including chronic active hepatitis. ${ }^{19}$ In addition, there are some reports of antibodies to native DNA occurring in the sera of patients receiving haemodialysis but who did not apparently have SLE. ${ }^{20}$ These results probably reflect the different methods and antigens used in the various systems reported. This is exemplified by the discrepancies noted in the Arthritis and Rheumatism Council's workshop laboratory study report on the measurement of anti-DNA antibodies where the concordance of assays for antibodies to double stranded DNA was noted to be 'good but not spectacular'. ${ }^{21}$ A number of studies have reported that not only the presence of single stranded DNA but single stranded regions within predominantly duplex DNA molecules may lead to the detection of antibodies to single stranded DNA and consequently loss of specificity and sensitivity. Attempts to resolve this problem with MAK and DEAE cellulose columns and $\mathbf{S}^{1}$ endonuclease digestion of native DNA preparations has met with considerable success in reducing this problem. However, using an ethidium bromide assay we have been able to demonstrate that not one of these techniques can be entirely relied upon to exclude DNA molecules containing single stranded regions. ${ }^{22}$

The use of synthetic poly dAT appears to solve a number of these problems. In particular, it is free of single stranded molecules or single stranded regions. In addition, its structure is uniform and therefore provides a useful antigen for not only day-to-day but also interlaboratory reference and standardisation. Although it might have limited antigenic potential and a limited antigenic spectrum when compared to native DNA, our study has shown that this synthetic antigen can be reliably 
used in the laboratory detection of antibodies which specifically react with duplex DNA and which are specific for SLE. These antibodies were not detected in the sera of other connective tissue diseases where previous reports had suggested that they might occur to native DNA preparations. These results are in accord with those published by Steinman et al. ${ }^{7}$ and Lentz et al..$^{13}$ but are discrepant with those of Chubick et al. ${ }^{23}$ for reasons that are not clear. Our study also demonstrates that antibodies to a well characterised native DNA preparation may occur in disease other than SLE but that antibodies to poly dAT are not detected. The probable explanation is the presence of single stranded regions within the native DNA preparation. Support for this suggestion is provided by the data on the correlation between the two different antibodies in sera from patients with SLE. The overall degree of correlation is good but is less so in those sera that contained abnormally high levels of antibody to one or other antigen. This was predominantly due to sera that bound only to the native DNA but not to the poly dAT, sometimes in high titre. As the native DNA is known to contain single stranded regions, this probably reflects binding by single stranded antibody which is not detected by the entirely duplex poly dAT.

Levels of DNA antibody appear from previous studies to correlate well with clinical evidence of disease activity in SLE. ${ }^{24}$ From our study the same also appears to be true for antibodies to poly dAT. There was a significant correlation between the presence of antibodies to poly dAT and clinical evidence of disease activity. This was true of all patients whether renal disease was present or not. These results are in contrast to those reported by Steinman et al.,25 who showed a significant correlation between poly dAT binding and renal histology. The probable explanation for this apparent discrepancy is that fewer of our patients were subjected to renal biopsy and histological assessment. It is possible, therefore, that some of our patients in the non-renal groups with elevated poly dAT binding may well have had abnormal renal histology if biopsy had been performed even though there was no clinical evidence of renal disease as assessed by active urinary sediment or proteinuria.

The value of poly dAT lies in its homogeneous character and its lack of single stranded regions. It would be of value in interlaboratory standardisation and would overcome some of the discrepancies reported, due to the considerable differences in size, structure, and source of native DNA preparations currently used. In our experience, it is more specific for SLE than native DNA and can be used equally well for serial monitoring of disease activity.

\section{References}

${ }^{1}$ Koffler D, Carr R, Agnello V, Thoburn R, Kunkel H. Antibodies to polynucleotides in human sera: antigenic specificity and relation to disease. J Exp Med $1971 ; 134: 294-312$.

${ }^{2}$ Hughes GRV, Cohen SA, Christian CL. Anti-DNA activity in systemic lupus erythematosus. $A n n$ Rheum Dis 1971;30:259-64.

${ }^{3}$ Pincus T, Schur PH, Rose JA, Decker JL, Talal N. Measurement of serum DNA binding activity in systemic lupus erythematosus. $N$ Engl J Med 1969; 281:701-5.

${ }^{4}$ Epstein W, Tan M, Easterbrook M. Serum antibody to double-stranded RNA and DNA in patients with idiopathic and secondary uveitis. $N$ Engl J Med $1971 ; 285: 1502-6$.

${ }^{5}$ Hahn B, Sharp GC, Irvin WS, et al. Immune responses to hydralazine and nuclear antigens in hydralazineinduced lupus erythematosus. Ann Int Med 1971;76: $365-74$.

${ }^{6}$ Davis P, Burrington M, Russell AS, Morgan AR. Analysis of DNA structure by hydroxyapatite columns and ethidium bromide fluorescence techniques. Arthritis Rheum 1978;21:407-13.

${ }^{7}$ Steinman CR, Deesomchok U, Spiera H. Detection of anti-DNA antibody using synthetic antigens. $J$ Clin Invest 1976;57:1330-41.

${ }^{8}$ Nygaard AP, Hall BD. A method for the detection of RNA-DNA complexes. Biochem Biophys Res Commun 1963;12:98-104.

9 Jones OW, Berg P. Studies on the binding of RNA polymerase to polynucleotides. J Mol Biol 1966;22: 199-209.

${ }^{10}$ Winfield JB, Davis JS. Anti-DNA antibody in procainamide-induced lupus erythematosus: determinations using DNA fractionated by methylated albumin-Kieselguhr chromatography. Arthritis Rheum 1974;17:97-110.

${ }^{11}$ Locker JD, Medof ME, Bennett RM, Sukhupunyaraksa S. Characterization of DNA used to assay sera for anti-DNA antibodies; determination of the specificities of anti-DNA antibodies in SLE and non-SLE rheumatic disease states. $J$ Immunol 1977;118:694-701.

${ }^{12}$ Levine L, Stollar B. Nucleic acid immune systems. Prog Allergy 1968;12:161-91.

${ }^{13}$ Lentz K, Winfield J, Barland P. Antibodies to dAT detected by membrane filtration. Arthritis Rheum 1976;19:867-73.

${ }^{14}$ Morgan A, Pulleyblank DE. Native and denatured DNA, crosslinked and palindromic DNA and circular covalently closed DNA analysed by a sensitive fluorometric procedure. Biochem Biophys Res Commun 1974;61:396-403.

${ }^{15}$ Carr RI, Hoffmann AA, Harbeck RJ. Comparison of DNA binding in normal population, general hospital laboratory personnel and personnel from laboratories studying SLE. J Rheumatol 1975;2: 178-83.

${ }^{16}$ Hanson V, Drexler E, Kornreich H. DNA antibodies in childhood scleroderma. Arthritis Rheum 1970;13: 
798-801.

${ }^{17}$ Sharp GC, Irvin WS, Tan EM, Gould RG, Holman HR. Mixed connective tissue disease-an apparently distinct rheumatic disease syndrome associated with a specific antibody to an extractable nuclear antigen (ENA). Amer J Med 1972;52:148-59.

${ }^{18}$ Bell C, Talal N, Schur PH. Antibodies to DNA in patients with rheumatiod arthritis and juvenile rheumatoid arthritis. Arthritis Rheum 1975;18: 535-40.

19 Davis P, Read AE. Antibodies to double-stranded (native) DNA in active chronic hepatitis. Gut 1975; 16:413-5.

${ }^{20}$ Nolph KD, Husted FC, Sharp GC, Siemsen AW. Antibodies to nuclear antigens in patients undergoing long-term hemodialysis. Amer J Med 1976;60: 673-6.

${ }^{21}$ Lachmann PJ, Petrie A. Analysis of results of the workshop study on measurement of anti-DNA antibodies. Ann Rheum Dis 1977;36:Suppl 1:76-81.

¿2 Davis P, Miller C, Riley C (in preparation). Comparison

of techniques for the purification of native DNA preparations. Analysis by ethidium bromide technique and effect on DNA binding in Millipore filter assay.

${ }^{23}$ Chubick A, Sontheimer RD, Gilliam JN, Ziff M. An appraisal of tests for native DNA antibodies in connective tissue diseases. Ann Intern Med 1978;89: 186-92.

${ }^{24}$ Lightfoot RW, Jr, Hughes GRV. Significance of persisting serologic abnormalities in SLE. Arthritis Rheum 1976;19:837-43.

${ }^{25}$ Steinman C, Grishman E, Spiera H, Deesomchok U. Binding of synthetic double-stranded DNA by serum from patients with systemic lupus erythematosus. Correlation with renal histology. Amer $J$ Med 1977;62:319-23.

Requests for reprints to: Dr P Davis, 9-112 Clinical Sciences Building, University of Alberta, Edmonton, Alberta, Canada T6G 2G3. 